\title{
Decisões em saúde no relacionamento entre o profissional e o paciente com transtorno alimentar
}

\author{
Health decision in the relationship between \\ professional and patient with \\ eating disorder
}

\author{
Laura Vilela e SOUZA ${ }^{1}$ \\ Manoel Antônio dos SANTOS ${ }^{2}$
}

\begin{abstract}
Resumo
O paciente diagnosticado com transtorno alimentar pode ser visto como alvo de orientação ou ser posicionado, junto ao profissional, como especialista na condução do tratamento. Buscou-se compreender, a partir das práticas discursivas de pessoas diagnosticadas com esses transtornos, como profissionais e pacientes constroem as decisões sobre o tratamento. Foram realizadas entrevistas com 12 pacientes de um serviço especializado na área, e quatro foram selecionadas para análise, que teve como fundamento o discurso construcionista social. A análise permitiu abordar os movimentos denunciativos das participantes com relação às decisões unilaterais tomadas por profissionais de saúde, e seu pleito por maior participação do paciente nas decisões do tratamento. Essas realidades relacionais foram discutidas a partir dos discursos sociais privilegiados nas práticas discursivas empreendidas no relacionamento profissional-paciente, da problematização da organização das políticas públicas em saúde em nosso país e do modo de funcionamento das instituições hospitalares.
\end{abstract}

Palavras-chave: Anorexia nervosa; Bulimia nervosa; Construcionismo social; Pessoal de saúde; Relações médico-paciente.

\begin{abstract}
The patient diagnosed with an eating disorder can be seen as a target for guidance or can be positioned, together with the professional, as a specialist in the performance of the treatment. We sought to understand, from the discursive practices of people diagnosed with these disorders, how professionals and patients construct decisions about treatment. Interviews were conducted with 12 patients in a specialized service and four of these were selected for analysis, based on the social constructionist discourse. The analysis allowed us to investigate the denunciative movements of the

V.

1 Universidade Federal do Triângulo Mineiro, Instituto de Educação, Letras, Artes, Ciências Humanas e Sociais, Departamento de Psicologia. Av. Getúlio Guaritá, 159, Centro Educacional, Sala 320, Abadia, 38025-180, Uberaba, MG, Brasil. Correspondência para/Correspondence to: L.V. SOUZA. E-mail: <lauravilelasouza@gmail.com>.

2 Universidade de São Paulo, Faculdade de Filosofia, Ciências e Letras de Ribeirão Preto, Departamento de Psicologia. Ribeirão Preto, SP, Brasil.

Artigo elaborado a partir da tese de L.V. SOUZA, intitulada "Construindo cuidado: a relação com os profissionais da saúde nas práticas discursivas de pessoas diagnosticadas com transtornos alimentares". Universidade de São Paulo, 2011.
\end{abstract}


participants regarding the unilateral decisions taken by the healthcare professionals, and their demand for greater patient participation in treatment decisions. These relational realities were discussed considering the social discourses privileged in the discursive practices undertaken in the physician-patient relationship, the structuring of public health policies in our country, and the functioning of hospitals.

Keywords: Anorexia nervosa; Bulimia nervosa; Social constructionism; Health personnel; Physician-patient relations.

Grande parte dos serviços hospitalares posiciona o paciente com Transtorno Alimentar (TA) como alvo de orientação e cuidado (Riikonen, 1999). Trata-se da posição do profissional como alguém "de cima de", como afirma Spink (2007), como aquele que detém a palavra final sobre os procedimentos em saúde.

Alguns discursos participam do posicionamento do profissional como especialista inconteste do tratamento. Um discurso que marca a atribuição desse lugar afirma o profissional como hierarquicamente superior ao paciente. Essa hierarquia se dá em virtude do acesso do profissional a um conhecimento mais acurado sobre o ser humano. O profissional é posicionado, então, como o agente que dita as normas sobre como a assistência terapêutica deve acontecer (Grandesso, 2000). Esse posicionamento favorece práticas normalizadoras, que podem impedir a participação plena do paciente nas decisões sobre o que é saúde e os modos como se dá seu restabelecimento.

Participa também dessa construção a noção de autonomia em saúde (Camargo-Borges, Mishima, \& McNamee, 2008). Ainda que a autonomia seja considerada um direito em saúde, cabe ao profissional tomar a decisão sobre se um paciente é ou não capaz de exercer sua autonomia. Uma das razões para uma pessoa não ser considerada autônoma seria a presença de um diagnóstico de psicopatologia. Nesse caso, a pessoa seria tomada como incapaz de exercer seu direito de opinar sobre o tratamento.

Nos transtornos alimentares como Anorexia Nervosa (AN) e Bulimia Nervosa (BN), a distorção da imagem corporal é considerada razão suficiente para ratificar a impossibilidade de as pessoas diagnosticadas responderem por suas ações em muitos momentos. Essa distorção indicaria o comprometimento das faculdades mentais da pessoa e
Psychiatric Association - APA, 2000). Desde a construção do TA como uma categoria psicodiagnóstica, seu tratamento basicamente tem sido caracterizado pelo controle absoluto do médico. O principal argumento elencado para justificar a necessidade desse controle é que os pacientes carecem de autonomia para tomarem decisões por conta própria (Hepworth, 1999).

William Withey Gull foi um dos primeiros médicos a descreverem, na década de 1870, o que viria a ser designado como AN. Esse pesquisador já alertava sobre os perigos dos médicos aceitarem fazer o que os pacientes queriam, uma vez que eles não estariam em condições de responder por sua saúde. Sobre isso, ele afirmou: "a inclinação do paciente [em alimentar-se] não deverá de forma alguma ser consultada" (Gull, 1874, p.24, tradução nossa). Ernest Charles Lasègue, outro pioneiro na descoberta médica da AN, abordou a falta de cooperação dos pacientes e suas características manipulativas (Vandereycken \& Van Deth, 1994).

Quando a autonomia é significada como uma capacidade individual, os fracassos no tratamento tendem a ser explicados em termos de julgamentos individuais. Esse movimento pode trazer, como alertam Camargo-Borges et al. (2008), um descomprometimento ético e social. Nesse contexto, não há espaço para os profissionais da saúde se perguntarem de que forma participam da construção desses fracassos.

Um questionamento desse tipo foi empreendido por Eivors, Button, Warner e Turner (2003), que, diante da elevada taxa de abandono do tratamento, investigaram as razões alegadas pelos pacientes com diagnóstico de AN para justificarem essa descontinuidade. Os participantes do referido estudo apontaram a falta de controle sobre o plano terapêutico como a principal razão para interromperem o tratamento. Nesse caso, segundo os pa- 
cientes entrevistados, a postura do profissional de decidir unilateralmente a direção do tratamento e a do paciente de ter de adequar-se a ele seriam as causas de muitas desistências.

Uma das possíveis razões para a dificuldade dos profissionais pensarem a construção conjunta do tratamento pode ser a impossibilidade de romper com as tradições em saúde, que constroem uma rígida hierarquia profissional-paciente. Um exemplo de uma possível mudança nessa hierarquia seria a participação dos pacientes nas reuniões de equipe, concedendo-lhes voz ativa na tomada de decisões relativas ao tratamento.

A pauta de discussão contemporânea sobre a garantia dos direitos dos pacientes na tomada de decisões em saúde e na busca pela horizontalidade na relação profissional-paciente oferece repertórios linguísticos alternativos para os relacionamentos em saúde (Spink, 2007). O acesso mais facilitado das pessoas às informações sobre direitos em saúde leva ao reposicionamento do paciente, desde uma postura passiva para uma postura questionadora. Essa postura questionadora implica reconhecer a exigência de esclarecimentos sobre os potenciais benefícios e prejuízos das ações em saúde propostas pelos profissionais (Marcolino \& Cohen, 2008).

Atualmente, alguns serviços de atendimento em TA, especialmente na Europa, têm mostrado preocupação com essa diferença hierárquica existente entre profissional e paciente. Os profissionais desses serviços colocam em discussão formas de posicionamento do paciente como especialista na condução do tratamento, lado a lado com o profissional (Honig, Dargie, \& Davies, 2006; Lock, Le Grange, Agras, \& Dare, 2001).

A especialidade do paciente é assumida como distinta da do profissional, mas de igual importância; aos poucos, os serviços que admitem rever essas concepções cristalizadas têm repensado suas diretrizes de tratamento e permitido relações mais horizontais.

Buscando conhecer como esse cenário se apresenta em um serviço brasileiro de assistência em TA, realizou-se uma pesquisa que focou, entre outros aspectos, a construção do relacionamento entre profissional e paciente nesse contexto. No presente artigo, é apresentado um recorte dessa investigação. O objetivo deste estudo é compreender de que maneira as práticas discursivas na relação profissional-paciente participam da construção das decisões nos tratamentos de saúde de pacientes com TA.

\section{Método}

Todos os pacientes atendidos há no mínimo um ano pelo serviço de assistência ambulatorial em AN e BN de um hospital-escola do interior paulista foram convidados para pesquisa. Esse intervalo mínimo de tratamento foi estipulado para garantir que os participantes tivessem um tempo significativo de relacionamento com os profissionais da equipe multidisciplinar de saúde. Doze mulheres, entre 12 e 45 anos de idade, aceitaram participar da pesquisa.

A produção dos dados ocorreu no período de janeiro a julho de 2008, por meio de entrevistas audiogravadas em fitas cassete e MP3. A entrevistadora era também psicóloga do serviço.

Utilizou-se a modalidade da entrevista por pauta, que "se guia por uma relação de pontos de interesse que o entrevistador vai explorando ao longo de seu curso" (Gil, 2008, p.112). Como mencionado, o projeto mais amplo de pesquisa tinha por objetivo focar não apenas o relacionamento profissional-paciente, mas também outros pontos de interesse, como, por exemplo, o modo como as pacientes entendiam seu problema relacionado ao comportamento alimentar, o que elas consideravam útil no tratamento, o que ajudava durante a internação hospitalar e de que forma a família as auxiliava a lidarem com a questão.

Na modalidade de entrevista por pautas, "o entrevistador faz poucas perguntas diretas e deixa o entrevistado falar livremente à medida que refere às pautas assinaladas" (Gil, 2008, p.112). Ao falarem sobre a pauta do relacionamento profissional-paciente, quatro das 12 participantes mencionaram dificuldades decorrentes de decisões tomadas por profissionais com relação a intervenções em saúde. Sensíveis às críticas contemporâneas sobre a não 
participação do paciente com TA nas decisões do tratamento (Honig et al., 2006), os autores deste trabalho consideraram relevante a análise pormenorizada desses relatos. Desse modo, essas quatro pacientes foram selecionadas como participantes deste estudo.

Como preconizado pelo discurso construcionista social, a apresentação dos fragmentos da entrevista deve preservar a sequência de falas entre pesquisador e participante, entendendo-a como ação conjunta (Guanaes \& Japur, 2008). De forma a preservar a sequência de falas das entrevistas realizadas, foi utilizada a estratégia das "delimitações temático-sequenciais" (Rasera \& Japur, 2003), que prevê a divisão das entrevistas em momentos e considera como marco delimitador de cada momento uma temática abordada. Após as entrevistas terem sido transcritas na íntegra e literalmente, foram recortados os momentos nos quais as participantes abordaram a questão das decisões no tratamento. O referencial teórico-metodológico das práticas discursivas e produção de sentidos (Spink \& Medrado, 2000) foi utilizado na análise qualitativa desse material.

Spink e Medrado (2000) definem práticas discursivas como "as maneiras a partir das quais as pessoas produzem sentidos e se posicionam em relações sociais cotidianas" (p.8). Esses autores não consideram o conceito de sentido como derivado de um mundo individual, mas como fruto das interações humanas.

Nesta proposta, a análise dos contextos discursivos transcorre de maneira temporal. Em uma análise de "tempo longo", busca-se o reconhecimento dos discursos institucionalizados presentificados na linguagem em uso. Em uma análise de "tempo vivido", são identificados os jogos de linguagem próprios da história de socialização de cada pessoa. Uma análise de "tempo curto" mostra os processos conversacionais no microcosmo da interação estabelecida face a face entre as pessoas (Spink \& Medrado, 2000) - o que corresponde, neste estudo, à interação entrevistadora-entrevistada.

O projeto foi aprovado pelo Comitê de Ética em Pesquisa da instituição hospitalar onde o estudo 78 foi realizado (Protocolo $n^{\circ}$ 7310/2007). Todas as participantes formalizaram sua anuência mediante assinatura do Termo de Consentimento Livre e Esclarecido. Os nomes das participantes e dos profissionais mencionados foram substituídos por pseudônimos para preservar seu anonimato.

As participantes são descritas a seguir: Catarina, 36 anos, em atendimento no serviço havia sete anos e meio, com diagnóstico de BN. Tália, 19 anos, em tratamento havia dois anos e meio, com diagnóstico de BN. Ilda, 45 anos, em tratamento havia 12 anos, com diagnóstico de AN. Natássia,18 anos, em atendimento havia três anos, com diagnóstico de BN.

\section{Resultados}

\section{Natássia}

Ao responder ao questionamento da entrevistadora sobre o que era positivo no relacionamento com os profissionais, Natássia relembrou um episódio que se deu por ocasião de um simpósio sobre TA, organizado pelo serviço pelo qual ela estava sendo cuidada. Na época, Natássia tomou conhecimento do evento e se inscreveu como participante, cumprindo os requisitos formais exigidos pelo evento. Todavia, próximo ao dia do evento, recebeu uma ligação da empresa organizadora do simpósio dizendo que ela não poderia mais participar, pois "as pessoas da equipe" - referindo-se aos profissionais - não tinham autorizado sua participação por ela não ser estudante universitária. Natássia contou ter ficado indignada com a decisão:

Natássia: É. Ela [Teresa, psicóloga do serviço] já ficou emocionada com uma situação minha... Eu achei isso tão bonitinho! Sabe? O ano passado... . Você participou do simpósio?

Entrevistadora: Eu fui.

Natássia: Então, eu ia também. Eu fiquei superfeliz, porque eu amo essas coisas. Eu fiquei superfeliz porque eles tinham deixado eu ir, sabe? Eu tinha conseguido o dinheiro, tinha conseguido fazer a inscrição. Chegou lá, na semana, tipo, dois dias antes de ter, a mulher lá liga, falando que eu não ia poder ir. Falei: "Como não?", "Ah, porque as 
pessoas da equipe não deixaram porque você não faz faculdade". Eu falei: "O quê?", vim aqui e dei "bafão". Falaram que não era aqui, era lá. Daí, tipo, eu fiquei puta da vida. Aí no grupo [de pacientes] eu chorei tanto, mas tanto, tanto, tanto! Porque eu fiquei muito chateada. Ela... Tipo, eu estava esperando aquilo há meses, sabe? Tinha lido muito sobre aquilo. Tinha um cara que ia vir, o doutor [nome do médico] lá, uma coisa assim, e eu sonhava com o cara, pagava um super pau para ele, né? E ele ia vir, ele acabou não vindo, né? Eu queria muito ver assim, sabe? Tipo, eu sabia que vocês tinham se empenhado muito com aquele trabalho, sabe? Eu queria poder prestigiar isso, sabe? E aí eu não pude. E aí foi uma pessoa que me ajudou muito - porque eu fui na porta do simpósio... . Não fui dar bafão, que eu não sou barraqueira, mas eu fui... porque são os meus direitos.

Nesse excerto de fala, é possível explorar os efeitos do discurso, mencionados por Spink (2007), que garante ao profissional um status social privilegiado pelo acesso exclusivo ao conhecimento científico. A formação universitária separa os especialistas em TA - os profissionais da saúde - e os leigos no assunto - os não profissionais. Nesse discurso, os profissionais têm o direito de decidir quem deve ou não transitar no espaço de um evento científico promovido por e para especialistas, como é o caso de um simpósio de TA.

\section{Tália}

Ao responder sobre o relacionamento profissional-paciente no tratamento da AN, Tália relembrou uma difícil experiência de internação:

Entrevistadora: Você chegou a ser internada?

Tália: Lá em [cidade de origem], minha cidade, não tem [tratamento], aí eu internei em [cidade próxima]. Eles me sedaram, aí eu tive crise compulsiva [sic] também, sabe? Tipo, eles me enfiavam comida assim, só que do mesmo jeito que eles enfiavam, voltava, mas não era porque eu provocava, não. Eu tive crise compulsiva e eles me chegaram a dopar, eu ficava assim, boba. Tudo que eles falavam pra mim eu fazia assim com a cabeça. Eu não tinha reação. Tudo que eles falavam pra mim, tudo que eles faziam, pra mim tava bom. Eu engordei dois quilos, mas eu não sabia, a hora que eu saí da internação, que eu caí por mim que eu tinha engordado dois quilos, eu fiquei louca. Aí eu comecei a malhar e fazer regime em cima de regime.

A atitude impositiva dos profissionais, mencionada por Tália, estaria legitimada pelo entendimento de seu descontrole emocional, de sua impossibilidade psicológica de cooperar voluntariamente com o tratamento. Assim, caberia ao profissional avaliar a extensão dessa (in)capacidade da paciente em poder ou não ter suas opiniões sobre si consideradas na proposição de seu tratamento (Camargo-Borges et al., 2008). A partir desses sentidos construídos, a internação seria o momento de total ausência de condições para o exercício consciente da autonomia por parte da paciente.

\section{Catarina}

O momento da entrevista de Catarina que foi selecionado para análise remete a uma decisão em saúde tomada fora do ambulatório de assistência em TA do hospital. Todavia, ele é aqui apresentado em razão dessa decisão ter sido tomada considerando-se o histórico de Catarina como paciente diagnosticada com BN.

Entrevistadora: Você saiu [do emprego]? Era estressante?

Catarina: Ai, eu acho que eu cheguei no meu limite, sabe? Eu já tava irritada com o HC. Eu vim aqui na [cirurgia] plástica, que eu fui chamada pra plástica, eles falaram que eu não podia fazer a plástica, porque eu não tenho alta da psiquiatria, eu falei: "Ah, pelo amor de Deus, por causa da psiquiatria eu não vou poder fazer plástica?". O meu sonho era fazer plástica, eu já ganhei a prótese, é que eu queria pôr peito, né? Não quero consertar o resto que não dá, eu ia ficar 10 anos fazendo plástica e não ia arrumar nada, mas a prótese do peito eu ganhei do meu namorado de presente de Natal no ano passado, já venho tentando tanto tempo falar com esse pessoal da plástica pra colocar pra mim. A 
hora que eu consigo, o médico senta na minha frente e fala assim: "Você não pode, porque o psiquiatra... . Você tá em tratamento". Eu falava: "Você tá brincando, né? Metade dos meus problemas vão se curar com essa plástica, moço, você não tá entendendo, [riso] eu não vou precisar nem do psiquiatra mais". Claro que não é assim, é lógico. Mas, na realidade, isso ia me fazer muito bem porque eu sempre tive complexo, mesmo quando eu era gorda, de ter pouco peito, não desenvolveu porque eu tive problema de hormônio. Então, eu sempre achei que isso seria o ideal, veio a cirurgia do estômago pra reduzir: "Ah, vamos emagrecer", lógico, também era uma coisa que me atormentava. Poxa, me barrar pra fazer plástica do peito foi demais. Aí eu fiquei muito estressada, aí eu falei: "Nossa! O duro que agora mudou tudo [os profissionais que a atendiam], os psiquiatras [do Ambulatório de Psiquiatria], mudou tudo a nutrição [os nutricionistas no serviço de TA], tudo, tudo, todo mundo aqui". Falei: "Agora mudou todo mundo". Aí no dia eu já fiquei me sentindo um lixo, aí eu falei: agora acabou mesmo, não posso mais ter esperança de nada, daqui um, sei lá quantos anos que eu vou sair dessa psiquiatria, eu já vou tá tão velha que eu não vou precisar mais pôr peito.

Como argumentado no discurso da autonomia (Camargo-Borges et al., 2008), ter conhecimento do histórico psiquiátrico de Catarina teria posicionado o médico como aquele que deveria, por princípios teóricos, técnicos e éticos, avaliar se a paciente era capaz de se responsabilizar por suas decisões. Como discutido, esse é o discurso da especialidade científica (Grandesso, 2000; Spink, 2007).

$\therefore \quad$ Catarina argumentou com o cirurgião plástico que u teria benefícios emocionais com a cirurgia. Todos esses argumentos participavam da construção da 3 decisão do médico como equivocada.

gação do médico que Catarina contou de seu incômodo com a mudança dos profissionais que a atendiam no ambulatório de psiquiatria e também no serviço de TA: "Nossa! O duro que agora mudou tudo [os profissionais que a atendiam], os psiquiatras [no Ambulatório de Psiquiatria], mudou tudo a nutrição [os nutricionistas no serviço de TA]". Com a realização de seu sonho atrelada à superação de seu transtorno emocional, Catarina precisaria garantir que os serviços nos quais ela se tratava oferecessem um tratamento adequado e abrangente. Essa postura de colocar nas mãos dos profissionais a responsabilidade por sua melhora pode ser entendida, no contexto de produção de sentidos de sua entrevista, não apenas como reflexo do uso do discurso do profissional como soberano especialista (Grandesso, 2000), mas também a partir das narrativas tecidas sobre os momentos de desacordos, vividos por Catarina, com os profissionais.

\section{Ilda}

Respondendo à pergunta da entrevistadora sobre o que poderia ajudar o paciente com TA durante sua internação hospitalar, Ilda contou sobre os atritos que vivenciara em suas experiências anteriores de internação:

Ilda: O pessoal falava que eu era muito manipuladora, que eu manipulava os residentes. Então que eles acharam que eu era desse jeito, o pessoal da psiquiatria a mesma forma. Eu fui mesmo estigmatizada. É uma coisa assim que eu não aceitei muito a conduta da equipe. O Dr. Álvaro [médico nutrólogo da equipe de internação] foi, assim, taxativo que não iria fazer, colocar outro cateter [para passar dieta por via parenterall; a Dra. Magda [médica residente], na época tava me acompanhando, que era uma residente no hospital, na época, ela também falou que não. Por ela não tinha nem colocado o primeiro. Quem fez força pra tá colocando foi a Dra. Eliana [outra médica residente da equipe de internação].

Entrevistadora: Quê que foi bom na relação com ela?

Ilda: A Dra. Eliana... eu acho que ela entendeu a minha carência de ser atendida na minha necessidade, no meu jeito de aceitar o tratamento. Melhorar a minha aceitação, aceitando a minha conduta também, a minha participação. Não que a minha conduta... . Conduta é do médico, mais do pessoal da equipe. Mas, assim, a minha 
participação na tomada de conduta, isso acho que me trouxe de bom, por parte dela. Ela me respeitou, ela respeitou a minha vontade, ela foi contra todo mundo, que lá o pessoal caiu em cima dela, caiu matando por causa do cateter.

Os "atritos" entre llda e a equipe, como decorrentes da discordância quanto à conduta a ser tomada com relação ao seu tratamento, podem ser entendidos a partir da disputa de poder com relação às posições ocupadas por paciente e profissional no âmbito das práticas em saúde (Spink, 2007). Como mencionado, a decisão sobre o que é melhor para o paciente, tradicionalmente, tem como referência a crença em conhecimentos cientificamente comprovados. O profissional é socialmente reconhecido como representante desse conhecimento (Grandesso, 2000).

Sendo assim, o paciente pode, considerando-se a força de ação desses posicionamentos, sentir-se na obrigação de acatar a decisão da equipe. A recusa nessa aceitação, como discutido, pode ser interpretada como resistência do paciente àquilo que foi considerado bom para ele (Camargo-Borges et al., 2008).

\section{Discussão}

Considerando-se o discurso sobre autonomia em saúde (Camargo-Borges et al., 2008), Natássia, ao ser diagnosticada como portadora de uma psicopatologia, não estaria em condições de responder pelas reações emocionais que poderiam ser desencadeadas ao participar do simpósio. Diante dessa construção hierárquica, ela poderia ter aceitado a decisão da equipe, validando seu lugar tradicional de saber. Todavia, ao posicionar-se como consumidora ferida em seus "direitos", Natássia posicionou a equipe como negligente. Foi desse lugar que conseguiu denunciar a injustiça da equipe e sua ingratidão.

No caso de uma paciente diagnosticada com TA, circular nos espaços de trânsito exclusivo do profissional equivale a conhecer "por dentro" os desafios de seu tratamento e a gravidade de seus sintomas (APA, 2000). A partir do discurso do diagnóstico, considera-se que a pessoa deve ter certa formação acadêmica para compreender essas informações de maneira adequada. Além disso, ao participar do simpósio organizado pelos profissionais do serviço no qual era atendida, Natássia poderia ouvir relatos referentes a outros pacientes atendidos ou até seu próprio histórico clínico. É comum nesses eventos científicos a exposição de estudos de caso e, como rezam as convenções médicas, considera-se que os pacientes não devam participar desses espaços.

Decorre dessa construção social a dificuldade em assumir os pressupostos de relações horizontalizadas entre profissionais e pacientes, como apontado por Honig et al. (2006). Fica, assim, inexequível a proposta de um atendimento em TA que possa ter a participação do paciente nos espaços de circulação do conhecimento científico, nas reuniões de equipe e no planejamento do tratamento.

Já o modo como Tália foi tratada como paciente mantém a lógica preconizada por Gull e Lasègue - mencionados na introdução deste estudo -, que, no século XIX, já consideravam as pacientes com TA como incapazes de participarem das decisões acerca do tratamento. Nessa vertente, a imposição das intervenções médicas seria uma medida necessária para o alcance da saúde (Crisp, 2002). O discurso da autonomia torna inteligível a ação dos profissionais, porém tem como prejuízo o fato de não se poder pensar em formas alternativas de entendimento da recusa alimentar da paciente, como, por exemplo, entender essa recusa como fruto das ações conjuntas entre a equipe e Tália durante sua internação.

A designada "crise compulsiva", que é entendida por algumas teorias psicológicas como fruto de uma condição psicopatológica individual (Vindreau, 2003), foi construída como uma resposta de Tália à atitude da equipe de profissionais. Diante das decisões tomadas pela equipe responsável pela internação, a paciente não assumia o lugar de passividade outorgado a ela. A construção dos comportamentos purgativos como resultante de uma postura impositiva e não negociada da equipe, antes de sustentar o argumento de uma psicopatologia individual, reforçava a denúncia de como os pro- 
fissionais de saúde podem colaborar para intensificar o sofrimento do paciente.

O fragmento da entrevista de Catarina aponta para a complexidade das realidades construídas em saúde (Spink, 2007). Coexistem diferentes discursos que convergem para a produção de sentidos sobre como devem acontecer as decisões no tratamento do TA: o discurso da autonomia versus o discurso da crítica ao psicodiagnóstico; o discurso da defesa da vida versus o discurso da defesa da participação do paciente no tratamento; o discurso da valorização do conhecimento profissional versus o discurso da valorização do conhecimento do paciente.

Como afirma Gergen (2009), esses discursos não podem ser julgados fora de seu contexto de produção: não podem ser considerados bons ou ruins em si mesmos, mas analisados a partir dos efeitos que se deseja produzir nas práticas profissionais em saúde. Na entrevista de Catarina, seu relato de desmotivação com o tratamento seria um alerta para que os profissionais que a atendiam pudessem repensar sua estratégia de cuidado. Como convidar para decisões conjuntas uma Catarina capaz de participar das decisões no tratamento e não uma Catarina paciente psiquiátrica?

A partir dos discursos negociados no contexto do tratamento hospitalar, Ilda foi posicionada pela equipe como "manipuladora". Esse é um adjetivo comum nas práticas discursivas em saúde mental e, especialmente, na literatura psicológica sobre os TA (Bruch, 1978). Segundo Ilda, o conhecimento prévio da equipe com relação a ela fazia com que, todas as vezes em que ela era internada, os profissionais esperassem dela o mesmo comportamento manipulador. Na tradição individualista estabelecida sobre identidade, tem-se a noção de que as pessoas são sempre as mesmas nos diferentes contextos interativos em que transitam. Essa tradição convida a uma construção de eu unificado, cristalizando uma única forma de ser nas relações (Gergen, 2009).

A partir do sentido comumente atribuído aos TA como psicopatologia, a manipulação seria um traço decorrente dos sintomas do transtorno. Dessa

82 forma, enquanto estivesse em tratamento, seria um comportamento esperado da pessoa. A doutora Eliana foi posicionada como a única profissional da equipe que concordou com a opinião de Ilda. Esse aspecto pode ter convidado a entrevistadora a perguntar sobre o que era significado como positivo na relação com essa médica. A partir desse convite, Ilda narrou de que forma os profissionais poderiam garantir a participação dos pacientes nas decisões sobre o tratamento.

Considerando sua carência, a equipe teria conseguido a colaboração de Ilda, pois ela entenderia que sua tentativa de participação também estaria sendo aceita pelos profissionais. A palavra conduta, no contexto de produção de sentidos em saúde, usualmente está relacionada a um comportamento prescritivo do profissional. Daí a correção que llda faz em sua própria fala ao substituir o termo "conduta" por "participação", demonstrando, assim, ter sensibilidade às diferenças determinadas pela hierarquia que regula a relação profissional-paciente (Camargo-Borges et al., 2008).

O sentido que fundamentava a opinião contrária dos profissionais à adoção desse procedimento era o do "risco" acentuado que ele implicava. A polarização das opiniões entre llda e a equipe pareceu estar relacionada à necessidade de ambos se posicionarem de maneira rígida, a favor ou contra a colocação do cateter. Essas posturas extremas, por sua vez, respondiam ao jogo de posicionamentos e forças implicados nas decisões em saúde, especialmente aquelas nas quais o paciente está em situação de risco iminente de vida, como já discutido.

Como responsável pela manutenção da vida do paciente, o profissional considera-se soberano em sua decisão e entende que não tem como dividir essa responsabilidade com ele. Nesse cenário, torna-se difícil a negociação de sentidos sobre as condutas terapêuticas, o que acentuou a relação tensa na qual Ilda e a equipe se engajaram durante o penoso procedimento de implementação do cateter central.

Este estudo abordou a decisão sobre a alimentação forçada de Tália, o veto à cirurgia plástica reivindicada por Catarina, a proibição da participação de Natássia no simpósio de TA e a tomada 
de decisão sobre as condutas das quais Ilda poderia ou não participar. Todas essas decisões ficaram nas mãos dos profissionais, devido ao entendimento de que o paciente estaria emocionalmente fragilizado e, portanto, seria incompetente para tomar parte delas com discernimento.

Esses relatos alertam para importantes desafios a serem enfrentados na construção de práticas colaborativas entre profissionais e pacientes engajados no tratamento do TA, tais como: superar o medo do profissional de perder seu lugar de especialista, atenuar a desconfiança em relação às especialidades do paciente, dado o estigma que ronda o diagnóstico de AN e BN, e buscar formas de escutar e validar as opiniões do paciente. Ao mesmo tempo, esses relatos apontam para a necessidade de mudanças estruturais nos serviços de atendimento em TA, que posicionam hierarquicamente a equipe e os pacientes e impedem o estabelecimento de trocas mais efetivas entre eles.

A possibilidade de assumir posicionamentos mais ativos em relação à construção do tratamento convive com a necessidade de receber ajuda para o sofrimento vivido. Como abrir mão do tratamento, se esse é o lugar socialmente legitimado como o mais indicado para ajudar essas pessoas a superarem seus problemas? Ou, em outros termos, como o paciente pode ocupar um lugar de "falar do meio de" (Spink, 2007) nas discussões sobre seu tratamento se muitas vezes suas condições financeiras o impedem, por exemplo, de buscar ajuda em outros serviços disponíveis na rede pública de saúde ou na rede privada? As realidades relacionais denunciadas pelas participantes deste estudo estão atravessadas por discussões mais amplas, sendo uma delas sobre a organização das políticas públicas em saúde em nosso país.

Uma vez que o discurso construcionista social entende linguagem como ação, alterar a forma de falar sobre o relacionamento profissional-paciente pode modificar o próprio relacionamento. O conceito de responsabilidade relacional de McNamee e Gergen (1999) pode colaborar para pensarmos em termos relacionais e não individuais, o modo como essa suposta fragilidade dos pacientes com TA tem sido capturada pelos profissionais de saúde. Esse conceito traz a noção de que aquilo que a pessoa é ou faz só adquire estatuto de realidade porque outras pessoas, em suas práticas discursivas, engajam-se na construção da pessoa dessa ou daquela maneira.

Nas histórias trazidas por Natássia, ao longo de sua entrevista, é possível perguntar: Qual Natássia estava reivindicando um espaço de participação no simpósio e um espaço mais fluido e flexível de conversação no tratamento? Qual Natássia estava sendo ouvida pela equipe? A partir do entendimento proporcionado pelo conceito de responsabilidade relacional, podemos afirmar que as ações e as atitudes de Natássia guardam relação com as ações da pessoa com quem ela se mantinha em interação. Ao mesmo tempo, as dificuldades de Ilda em aceitar as intervenções da equipe de saúde passariam a ser investigadas a partir das ações conjuntas entre a paciente e os profissionais. Quais ações conjuntas convidavam ao jogo de posicionamento entre uma llda resistente e uma equipe impositiva? A partir do uso desse enfoque conceitual, o regime e a malhação recorrentes de Tália não seriam mais entendidos apenas como sinais e sintomas de um transtorno psiquiátrico, mas a partir dos cenários relacionais que se delineiam entre a paciente e a equipe.

Estudos futuros deverão caminhar nessa direção, buscando outras formas de linguagem para a (re)definição de saúde, doença, cuidado e tratamento. A partir da epistemologia construcionista social, entende-se que pesquisa é intervenção. Sendo assim, investigações que explorem outras formas de linguagem sobre a participação do paciente nos rumos do tratamento poderão fomentar a construção de realidades alternativas. Devem ser exploradas propostas de assistência inclusivas, nas quais possam conviver múltiplas verdades em saúde, superando a conhecida hegemonia do discurso biomédico. Será necessário, especialmente, incluir na agenda uma discussão sobre em quais casos o diagnóstico de TA é necessário, a quem ele realmente ajuda, de que forma e em que momento do tratamento ele auxilia.

Nesse sentido, investigações apreciativas poderão ser realizadas, buscando focalizar não os rela- 
tos de conflitos que emergem no relacionamento entre profissional e paciente, mas as histórias de sucesso observadas nessas relações. Pesquisas construcionistas sociais com foco apreciativo têm como objetivo convidar as pessoas a narrarem episódios positivos sobre um dado aspecto investigado (Souza, McNamee, \& Santos, 2010). No caso das decisões a serem tomadas no tratamento do TA, a meta é investir em formas alternativas de descrever os modos como podem ser negociadas e delimitadas as fronteiras do espaço de cuidado.

Outro potencial para pesquisas futuras encontra-se nas propostas contemporâneas de investigações colaborativas. Pesquisadores construcionistas sociais têm investido em formatos de pesquisa que garantam a participação dos indivíduos em todas as decisões do projeto a ser realizado (Souza et al., 2010). Desse modo, os participantes têm voz ativa na definição dos objetivos da pesquisa, no julgamento de sua utilidade, em seu delineamento e na publicação dos resultados. O valor desse tipo de estudo está em seu potencial de convidar pessoas a se engajarem em ações que visem transformações sociais relevantes.

\section{Referências}

American Psychiatric Association. (2000). Diagnostic and statistical manual of mental disorders. Washington, DC: Author.

Bruch, H. (1978). Golden cage: The enigma of anorexia nervosa. Cambridge: Harvard University Press.

Camargo-Borges, C., Mishima, S., \& McNamee, S. (2008). Da autonomia à responsabilidade relacional: explorando novas inteligibilidades para as práticas de saúde. Gerais: Revista Interinstitucional de Psicologia, 1(1), 8-19.

Crisp, A. (2002). Treatment of anorexia nervosa: Is 'where' or 'how' the main issue? European Eating Disorders Review, 10(4), 33-40.

Eivors, A., Button, E., Warner, S., \& Turner, K. (2003). Understanding the experience of drop-out from treatment for anorexia nervosa. European Eating Disorders Review, 11(2), 90-107.

Gergen, K. J. (2009). Relational being: Beyond self and community. New York: Oxford University Press.

Gil, A. C. (2008). Métodos e técnicas de pesquisa social (6 ${ }^{\mathrm{a}}$ ed.). São Paulo: Atlas.
Grandesso, M. (2000). Reconstrução do significado: uma análise epistemológica e hermenêutica da prática clínica. São Paulo: Casa do Psicólogo.

Guanaes, C., \& Japur, M. (2008). Contribuições da poética social à pesquisa em psicoterapia de grupo. Estudos de Psicologia (Natal), 13(2), 117-124.

Gull, W. W. (1874). Anorexia Nervosa (Apepsia Hysterica, Anorexia Hysterica). Transactions of the Clinical Society, 7(1), 22-27.

Hepworth, J. (1999). The social construction of anorexia nervosa. London: Sage Publications.

Honig, P., Dargie, L., \& Davies, S. (2006). The impact on patients and parents of their involvement in the training of healthcare professionals. European Eating Disorders Review, 14(4), 263-268.

Lock, J., Le Grange, D., Agras, W. S., \& Dare, C. (2001). Treatment manual for anorexia nervosa. London: The Guilford Press.

Marcolino J. A. F., \& Cohen, C. (2008). Sobre a correlação entre a bioética e a psicologia médica. Revista da Associação Médica Brasileira, 54(4), 363-368.

McNamee, S., \& Gergen, K. J. (1999). Relational responsibility: Recourses for sustainable dialogue. Thousand Oaks: Sage publications.

Rasera, E. F., \& Japur, M. (2003). Grupo de apoio aberto para pessoas portadoras do HIV: a construção da homogeneidade. Estudos de Psicologia, 8(1), 55-62.

Riikonen, E. (1999). Inspiring dialogues and relational responsibility. In S. McNamee \& K. J. Gergen (Eds.), Relational responsibility: Resources for sustainable dialogue (pp.139-149). Thousand Oaks: Sage.

Souza, L. V., McNamee, S., \& Santos, M. A. (2010). Avaliação como construção social: investigação apreciativa. Psicologia e Sociedade, 22(3), 598-607.

Spink, M. J. P. (2007). Sobre a possibilidade de conciliação do ideal da integralidade nos cuidados à saúde e a cacofonia da demanda. Saúde e Sociedade, 16(1), 18-27.

Spink, M. J. P., \& Medrado, B. (2000). Produção de sentidos no cotidiano: uma abordagem teórico-metodológica para análise das práticas discursivas. In M. J. P. Spink (Org.), Práticas discursivas e produção de sentidos no cotidiano: aproximações teóricas e metodológicas (pp.41-61). São Paulo: Cortez.

Vandereycken, W., \& Van Deth, R. (1994). From fasting saints to anorexic girls: The history of self-starvation. New York: University Press.

Vindreau C. (2003). A bulimia na clínica psiquiátrica. In B. Brusset, C. Couvreur \& A. Fine (Orgs.), A bulimia (pp.81-102). São Paulo: Escuta.

Recebido em: 18/8/2011

Versão Final em: 17/5/2012

Aprovado em: 6/6/2012 